\title{
Cell Populations in Lesions of Cutaneous Leishmaniasis of Leishmania (L.) amazonensis-infected Rhesus Macaques, Macaca mulatta
}

\author{
VF Amaral, C Pirmez*, AJS Gonçalves*, V Ferreira**, G Grimaldi Jr/ ${ }^{+}$
}

Departamento de Imunologia *Departamento de Bioquímica e Biologia Celular e Molecular, Instituto Oswaldo

Cruz **Departamento de Primatologia-Fiocruz, Av. Brasil 4365, 21045-900 Rio de Janeiro, RJ, Brasil

The cellular nature of the infiltrate in cutaneous lesion of rhesus monkeys experimentally infected with Leishmania (L.) amazonensis was characterized by immunohistochemistry.

Skin biopsies from infected animals with active or healing lesions were compared to non-infected controls (three of each type) to quantitate inflammatory cell types. Inflammatory cells (composed of a mixture of T lymphocyte subpopulations, macrophages and a small number of natural killer cells and granulocytes) were more numerous in active lesions than in healing ones. T-cells accounted for $44.7 \pm$ $13.1 \%$ of the infiltrate in active lesions (versus $C D 2+=40.3 \pm 5.7 \%$ in healing lesions) and $T$-cell ratios favor CD8+ cells in both lesion types. The percentage of cells expressing class II antigen (HLA$D R+)$ in active lesions $(95 \pm 7.1 \%)$ was significantly higher $(P<0.005)$ from the healing lesions $(42.7 \pm$

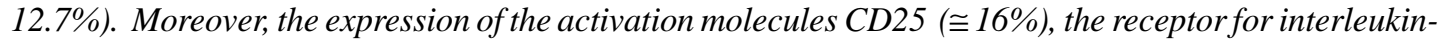
2, suggests that many $T$ cells are primed and proliferating in active lesions. Distinct histopathological patterns were observed in lesions at biopsy, but healing lesions contained more organized epithelioid granulomas and activated macrophages, followed by fibrotic substitution. The progression and resolution of skin lesions appears to be very similar to that observed in humans, confirming the potential for this to be used as a viable model to study the immune response in human cutaneous leishmaniasis.

Key words: Leishmania (L.) amazonensis - Macaca mulatta - experimental leishmaniasis - systemic and local cellular immunity

The outcome of leishmanial infection in humans depends largely on the immune responsiveness of the host and the virulence of the infecting parasite strain. The protozoa in this genus are capable of producing a broad spectrum of disease in humans, ranging from asymptomatic infection to disfiguring forms of mucosal leishmaniasis (ML) or the potentially fatal visceral form (kala-azar).

The data presented in this paper have been submitted by VF Amaral as part of a thesis for a $\mathrm{PhD}$ degree in Cellular and Molecular Biology at the Oswaldo Cruz Institute/Fiocruz, Rio de Janeiro, RJ, Brazil. Present address: Departamento de Imunobiologia, Universidade Federal Fluminense, Outeiro de São João Batista s/n, Niteroi, RJ, Brasil.

This work was supported in part by grants from the UNDP/World Bank/WHO Special Program for Research and Training in Tropical Diseases, Faperj and CNPq/ RHAE Program (Brazil).

${ }^{+}$Corresponding author. Fax: + 55-21-280-1589. E-mail: grimaldi@gene.dbbm.fiocruz.br

Received 2 August 1999

Accepted 6 December 1999
The more benign self-healing cutaneous leishmaniasis (CL) forms usually result in protection against reinfection, and cell-mediated immunity is involved in this protection (Grimaldi \& Tesh 1993).

The use of murine models for the identification of T-cell subsets secreting defined patterns of cytokines that lead to strikingly different effector functions has greatly improved our understanding of the regulation of the immune response involved in host resistance and susceptibility to Leishmania infection (Mossman \& Moore 1991). The innate or acquired capacities of macrophages for killing intracellular amastigotes appear ultimately to eliminate or control leishmanial infection. The current hypothesis is that T-cell-mediated macrophage activation is the major protective mechanism; resistance to infection is associated with a $T_{H} 1$ cytokine profile, characterized principally by interferon- $\gamma$ (IFN- $\gamma$ ), interleukin (IL) IL-2, and IL12 production, whereas susceptibility is dependent of $\mathrm{T}_{\mathrm{H}} 2$ cytokines, with secretion of IL-4, IL-5, and IL-10 (Heinzel et al. 1995).

Research on clinical immunology of leishmaniasis has shown that a marked heterogeneity characterizes the local immune response in the course 
of CL (Barral et al. 1987, Castes et al. 1989, Martinez-Arends et al. 1991, Esterre et al. 1992, Lima et al. 1994, Isaza et al. 1996). Differential expression of cytokines parallels the variation observed on the nature of the cellular inflammatory infiltrate (Modlin et al. 1985, Nilsen \& Mshana 1987, Pirmez et al. 1990a). T lymphocytes reactive to leishmanial antigens contribute to protective immunity, but may also participate in the development of chronic and destructive mucosal lesions (Conceição-Silva et al. 1990, Pirmez et al. 1990a, 1993). The pathogenesis of CL may be explained by the balance of CD4+ type 1 and CD8+ type $2 \mathrm{~T}$ cells, which have distinct $\mathrm{T}$ cell repertoires and may recognize distinct sets of antigens (Uyemura et al. 1993, Russo et al. 1993). However, the mechanisms leading to preferential induction and/or expansion of distinct $\mathrm{T}_{\mathrm{H}}$ cell subsets are still not well understood.

Non-human primates of several species, although to a lesser extent than inbred strains of mice, have also been used for studying immune response to Leishmania (Lainson \& Bray 1966, Dennis et al. 1986, Lujan et al. 1986, 1987, Pung \& Kuhn 1987, Olobo et al. 1992, Curry et al. 1994, Amaral et al. 1996). The availability of these experimental models is desirable, since they will provide valuable data on the efficacy of newly developed vaccines and the immunotherapeutic agents against leishmaniasis. We have previously examined (i) the susceptibility of Macaca mulatta to $L$. $(L$.) amazonensis infection and the clinico-pathologic changes of the disease and (ii) the immunological profile of the host occurring during primary and challenge infections (Amaral et al. 1996). The purpose of this study was to further characterize the local T-cell responses associated with cure of cutaneous lesions in this experimental host.

\section{MATERIALS AND METHODS}

Animals - A total of nine laboratory-bred and reared young adult (5 to 7 years old) rhesus macaques (M. mulatta) of both sexes, obtained from the Oswaldo Cruz Foundation Primate Research Center (Rio de Janeiro, Brazil), were used. The animal facility is maintained according to the guidelines of the Committee on the Care and Use of Laboratory Animals of the Institute of Laboratory Animal Resources, National Research Council, and the HHS (MD, USA). Animals were housed indoors in individual steel squeeze-back cages in a temperature $\left(25^{\circ} \mathrm{C}\right)$ - and humidity $(60 \pm 5 \%)$ - controlled environment. The monkeys were acclimatized to the laboratory conditions for at least two weeks before the experimental procedures begun. Animals were anesthetized before infection and prior to each sampling or testing pro- cedure. Monkeys were initially restrained in their cages, and subsequently were given, intramuscularly, Ketamine (Ketalar: Ketamine hydrochloride; Parke Davis) for anesthesia.

Experimental infection - Animals $(\mathrm{n}=6)$ were infected by intradermal inoculation of $10^{8}$ virulent promastigotes of $L$. (L.) amazonensis (strain MHOM/BR/77/LTB0016) in the upper eyelid. Lesion area was calculated using the formula $\pi r_{1} r_{2}$, as described by Wilson et al. (1979).

Leishmanin skin test (LST) and serological studies - The evaluation of delayed type hypersensitivity (DTH) responses to $L$. (L.) amazonensisderived leishmanin was done as described (Agwale et al. 1998). The tests (reactions measured as skin indurations at the site of injection) were read after 48 or $72 \mathrm{~h}$ using the ballpoint pen method. Classspecific (IgM and $\operatorname{IgG}$ ) antibodies against Leishmania were detected using indirect immunofluorescence (IFA) as described (Grimaldi et al. 1980). Each individual serum was tested in serial twofold dilutions [1:10 to $1: 640]$ in PBS. Pooled normal monkey serum and pooled human cutaneous leishmaniasis serum were included in each analysis as negative and positive control, respectively.

Lymphocyte blastogenesis assay - The methods described (Lujan et al. 1986, Amaral et al. 1996) were followed for peripheral blood leukocytes (PBL) preparation and proliferation assays. Purified PBL were cultured at $2 \times 10^{6}$ viable cells $\mathrm{ml}^{-1}$ in the presence of optimal culture concentration of mitogen (PHA-P at $12.5 \mu \mathrm{g} \mathrm{ml}^{-1}$; Sigma) or parasite antigen (10 $\mu$ g protein/well). The soluble antigens for in vitro blast transformation assays were prepared from L. amazonensis promastigotes, according to the method described by Dennis et al. (1986). Cultures were incubated at $37^{\circ} \mathrm{C}$ in a humidified atmosphere containing $5 \% \mathrm{CO}_{2}$ for three days in the case of mitogen or for four days in the case of antigens. The cells were pulsed with $\left[{ }^{3} \mathrm{H}\right]$ thymidine (Amersham, Co., U.K.; $1 \mu \mathrm{Ci} / \mathrm{well}$; $5 \mu \mathrm{Ci} / \mathrm{m} M$ ) over the last $18 \mathrm{~h}$ and harvested onto glass fiber filter mats (Titertek, FlowLab, U.S.A.). Radioactive incorporation into DNA was determined by liquid scintillation spectrometry. Results were expressed as stimulation index (SI), which was obtained by dividing the proliferations of test cultures by proliferation of control cultures. The data from the lymphocyte proliferative responses (LPR) were compared with those of healthy animals (control group) using the unpaired Student's $t$-test.

Tissue preparation - Skin biopsies were removed from the border of selected cutaneous lesions during active (6-8 wk p.i) and healing stages (11-13 wk p.i.) of the infection using a $3-\mathrm{mm}$ punch and embbeded in OCT (Tissue Tek; Miles Inc., 
Naperville, IL). Naive animals $(\mathrm{n}=3)$ were studied for characterizing the distribution and immunophenotype of lymphocyte subpopulations in normal rhesus skin. The samples were snap frozen and stored in liquid nitrogen until processed. Portions of the biopsies were used for routine histopathologic studies.

Immunoperoxidase staining - Cryostat sections 4-5 $\mu \mathrm{m}$ thick were air-dried and fixed in acetone. After rehydratation with phosphate buffered saline (PBS), serial sections of each specimen were stained with a biotin-avidin immunoperoxidase technique using the following monoclonal antibodies (mAbs): CD2 (T11 pan T cell antibody; Coulter), CD4 (IOR ${ }^{\circledR}$ helper/inducer $\mathrm{T}$ cell subset antibody; CIMAB, Havana, Cuba), CD8 (Leu 2a suppressor/cytotoxic $\mathrm{T}$ cell subset antibody; Becton-Dickinson, San Jose, CA), CD23 (Leu 20 antibody for B cells, Becton-Dickinson), and CD16 (Leu-11 antibody for NK cells, granulocytes, activated monocyte, imature fetal $\mathrm{B} / \mathrm{T}$ cells and macrophages; Becton Dickinson). Also used were mAbs anti-HLA-DR (which identifies B cells, monocytes, macrophages and activated $\mathrm{T}$ cells; Becton Dickinson) and anti-CD25 (for IL-2 receptor; Becton Dickinson). Whenever possible, a second $\mathrm{mAb}$ of a similar specificity but from different commercial sources was used in a cross-checking strategy. The sections were blocked with normal goat serum, then incubated with the primary murine $\mathrm{mAb}$ (at a concentration predetermined by checkerboard titration), followed by biotin-labeled anti-mouse antibody. After incubation with streptavidin-peroxidase complex (Amersham, UK), the sections were developed with the chromogen 3,9 amino-ethyl-carbazole (AEC, Sigma) plus $0.03 \%$ hydrogen peroxide in $0.01 \mathrm{M}$ acetate buffer pH 5.0. Slides were counterstained with Mayer's hematoxilin. Controls included untreated sections. The percentage of cells reacting with each $\mathrm{mAb}$ in relation to the total number of cells was determined as described by Esterre et al. (1992). Depending on the number of cells within the infiltrate, the whole section or 10 microscopic fields (magnification $\mathrm{x} 250$ ) were evaluated blind by two independent observers. To normalize the results, the total number of cells and the number of positive cells were calculated per square millimetre of inflammatory infiltrate (Sobel et al. 1984, Ridel et al. 1988) and the result given as a mean percentage \pm SD of positive cells within the granuloma. The data were analyzed using Student's $t$-test.

\section{RESULTS}

Immunologic features - The immunologic responses during infection were determined by LST, LPR, and measurements of antibodies. Individual cell-mediated immune responses to leishmanial antigens varied in the course of CL in $L$. $(L$.) amazonensis-infected rhesus monkeys, but specific DTH reactivity (mean \pm SD of LST size at $14 \mathrm{wk}$ p.i; $8.0 \pm 3.0$ ) and LPR of PBL (mean \pm SD of SI at 14 wk p.i; $9.0 \pm 3.9$ ) were detected in all animals, and both immune responses persisted beyond apparent self-cure (PBL of animals were comparably responsive to control mitogen PHA prior to and throughout infection). Both IgM and IgG responses to promastigote antigens rose during infection and then declined. IgM titers peaked (1:40) at 2 wk p.i.; IgG levels were detectable 2 wk p.i. and subsequently continued to increased, peaking $(1: 130)$ at 10 wk p.i. after which levels declined (1:30) in animals with healing lesion.

Lesion development - All L. (L.) amazonensisinfected animals developed skin lesions at the site of inoculation. Lesion development progressed as follows: the skin lesions (of an erythematous-papular nature) were first visible at $1-2 \mathrm{wk}$ p.i., then the developing nodular lesion progressed rapidly (nodules varying between approximately 20 to 120 $\mathrm{mm}^{2}$ ), peaking at 8 to 15 weeks p.i. All lesions ulcerated (after 6-8 wk p.i.) and were subsequently followed by regression and healing.

Pathology - Biopsies were obtained from infected animals with active $(\mathrm{n}=3)$ or healing $(\mathrm{n}=$ 3) lesions and skin sections were stained with either hematoxylin and eosin stains or specific mAbs for cell typing and quantitate the relative numbers of cells in the inflammatory infiltrate. In early phases of developing ulcerated skin lesions, indistinctly delimited and more or less differentiated macrophage accumulations were found (which encircled a central area of vacuolated macrophages, with or without intracellular parasites), and then evolved to the formation of granulomatous nodules. The granulomas were surrounded by a diffuse mononuclear infiltrate containing giant cells. In late stages, fibroblasts proliferated at the periphery of the granulomas and finally invaded them with fibrotic substitution.

The relationship between lesion type and the size/profile of the cellular infiltrate was examined. The mean \pm SD area of skin inflammatory infiltrates (composed of a mixture of $\mathrm{T}$ lymphocyte subpopulations, macrophages and a small number of natural killer cells and granulocytes) in developing nodular lesions $(2.4 \pm 0.9 \mathrm{~mm})$ was greater $(p<0.05)$ than that obtained in lesions $(0.4 \pm 0.1$ $\mathrm{mm}$ ) during the healing process.

All positive and negative cells from each field were counted. Fig. 1 shows the profile and percentage of positive cells in the cellular infiltrate; also illustrated (Fig. 2) are some of the results obtained on the characterization of cells. T-cells 


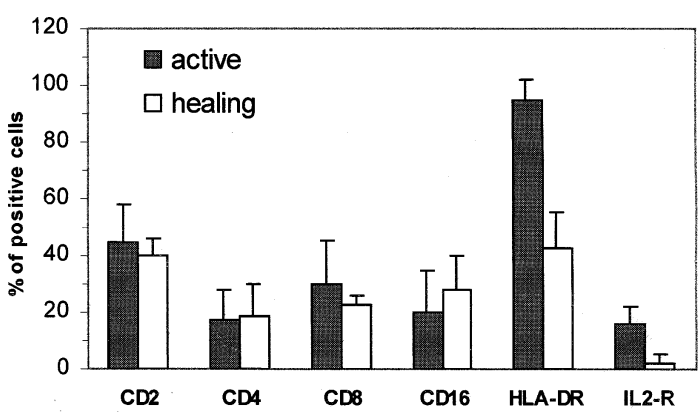

Fig. 1: cell type and relative numbers of cells in the inflammatory infiltrate of active and healing skin lesions. Cryostat sections were stained with monoclonal antibodies and the cells were enumerated as described in the Materials and Methods. Bars show the mean $\pm \mathrm{SD}$.

(CD2+) accounted for $44.7 \pm 13.1 \%$ (with a local CD4 $(17.5 \pm 10.6 \%) / C D 8(30.0 \pm 15.3 \%)$ ratio of $0.7 \pm 0.6$ ] of the infiltrate in active lesions [versus $\mathrm{CD} 2+=40.3 \pm 5.7 \%$; with a local CD4 $(18.7 \pm$ $10.9 \%) / \mathrm{CD} 8(23.0 \pm 3.0 \%)$ ratio of $0.8 \pm 3.7$ in healing lesions]. The percentage of cells expressing HLA-DR antigen in the active lesion group (95 $\pm 7.1 \%)$ was significantly higher $(p<0.005)$ from the healing lesion group $(42.7 \pm 12.7 \%)$. In comparison to the expression of class II antigens, the percentage of $\mathrm{T}$ cells bearing IL-2 receptors (CD25+ phenotype) present in the inflammatory infiltrate was lower in either active $(16.0 \pm 5.7 \%)$ or healing $(2.0 \pm 3.5)$ lesions. We observed a variable but moderate percentage of cells with the NK phenotype $(\mathrm{CD} 16+$ cells $=20.0 \pm 15.0 \%$ and 28.3 $\pm 12.0 \%$ in active and scarring lesions, respectively) and only few B lymphocytes (CD20+ cells $\cong 2 \%$ ) in the infiltrate.

Moreover, skin sections from naive animals were studied as controls. Small numbers of CD2+ cells were found in the epidermis and/or dermis, clustered mainly around postcapillary venules of the papillary vascular plexus or adjacent to cutaneous appendages. Most of these cells were CD8+ and presented an activated phenotype (HLA-DR+), but they did not express CD25 antigen on their surface.

\section{DISCUSSION}

A variety of Old World and New World monkeys are susceptible to infection with various human pathogens, but the issue of pathological consequence and mimicry of the human disease state is not clear cut in these animals as it is with the great apes (Kennedy et al. 1997). Non-human primate model is an animal system closer in term of immunological responses to humans (Letvin et al. 1983, Klein et al. 1993, Kennedy et al. 1997). The closer phylogenetically the Old World monkey species is to humans, the better the cross-reactivity with anti-human reagents. The majority of antihuman $\mathrm{CD}$ antigen reagents cross-react with Old World monkey species, although differences among species are observed (Letvin et al. 1983, Klein et al. 1993).

The characteristic clinical and pathologic features of the self-healing CL in humans were observed in $M$. mulatta experimentally infected with L. (L.) amazonensis, confirming the potential for this to be used as a primate model to study the immune response in human disease. The findings indicate that systemic immune responses (both humoral and cell-mediated) developed in infected animals correspond to those for human CL. In the original model description (Amaral et al. 1996), the results also show that the circulating $\mathrm{T}$ cell subpopulations from the infected monkeys vary throughout the course of infection. In early phases of infection blood CD4+ T cells appear to predominate (6-8 wk p.i.; CD4:CD8 mean ration, 5.0; range 2.5-7.1), but subsequently, an increase in CD8+ T cells was observed (15-21 wk p.i.; CD4:CD8 mean ration, 1.05; range 0.37-2.1).

Here we have characterized the cellular nature of the infiltrate in the skin lesion of rhesus macaques infected with the same parasite. Frozen skin biopsies from animals with active or healing lesions and non-infected controls were stained with a panel of mAbs to quantitate the cell types. Distinct histopathological patterns were observed in different lesions at biopsy, but there was predominance of lymphocytes and/or macrophages in the inflammatory infiltrate; granulomas showed a mixture of T-cell subpopulations with the ratio of helper:suppressor phenotypes less than one. The percentage of cells in the granulomas expressing the major histocompatibility complex (MHC) class II antigens in active lesions was significantly higher from the healing lesions. Results similar to ours were previously reported, studying the infiltrate in the skin of humans with CL (Pirmez et al. 1990b, Lima et al. 1994). Moreover, approximately $16 \%$ of the intralesional lymphocytes expressed IL-2 receptors, indicating that these activated cells were expanded when in contact with the parasite antigens. In spite of wide variations from one infected animal to another (as shown by some large SD values), the data show that the cell types and percentages of each cell type change uniformly during the infection, suggesting that the same components of the immune response are working in unison, at least at the level of the listed cell markers.

In humans, the intralesional immune response is heterogenous during the course of CL. Differential expression of cytokines parallels the variation observed on the nature of the cellular inflam- 

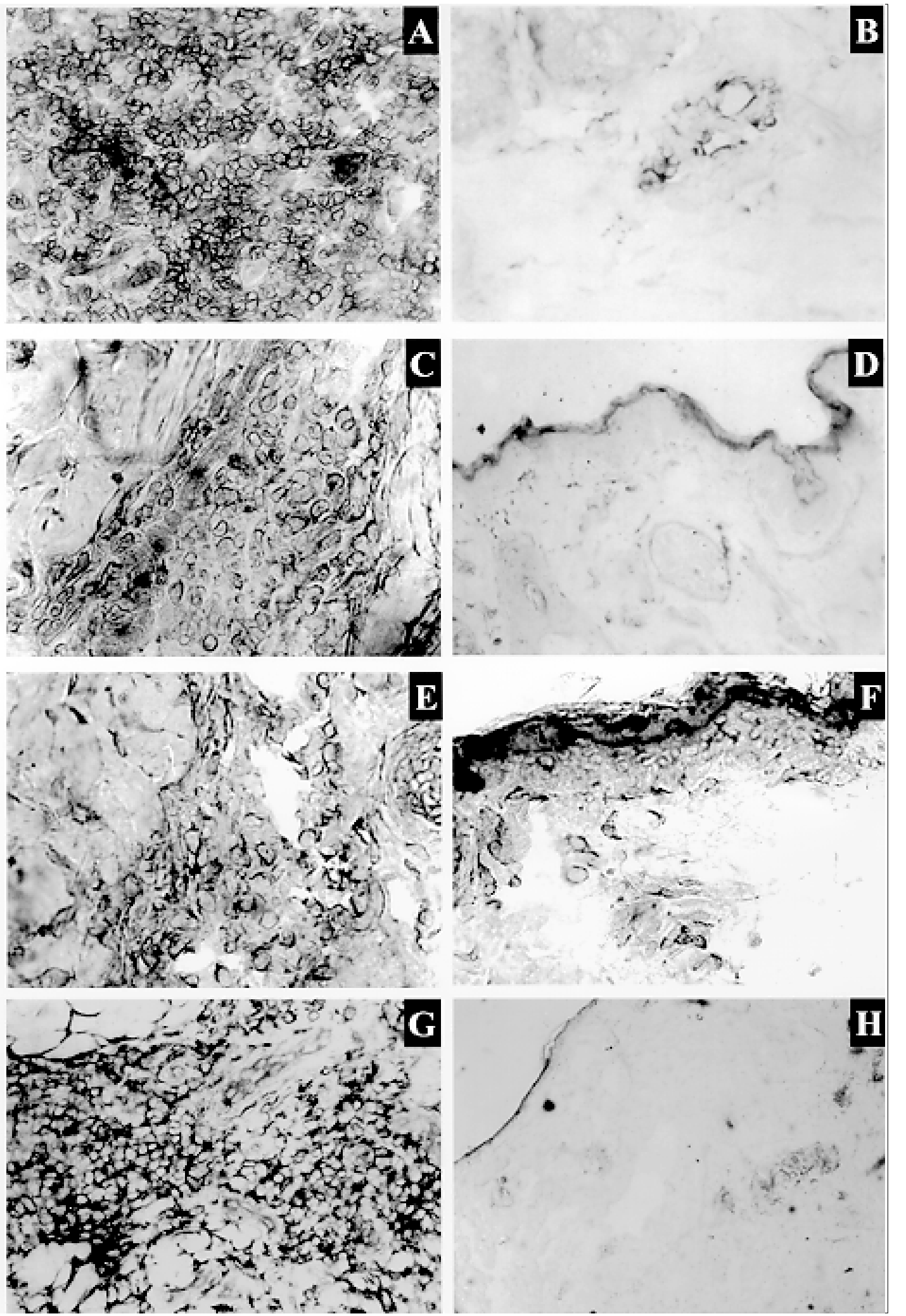

Fig. 2: cell populations in cutaneous leishmaniasis of Leishmania (L.) amazonensis-infected Macaca mulatta. Immunostaining of lesions (left column: active; right column: healing), using human anti-CD2 (A,B), anti-CD4 (C, D), anti-CD8 (E, F) and anti-HLA$\mathrm{DR}(\mathrm{G}, \mathrm{H})$ monoclonal antibodies, respectively. 
matory infiltrate, with particular reference to the $\mathrm{T}$ cell phenotypes (Modlin et al. 1985, Nilsen \& Mshana 1987, Pirmez et al. 1990a). T-cells bearing $\gamma \delta$ antigen receptors responding to infection (Modlin et al. 1989) are specifically selected by a limited set of antigens (Russo et al. 1993) and expanded within microanatomic region (Uyemura et al. 1992).

Most reports concerning characterization of cells in active skin lesions of patients with CL have shown that $\mathrm{T}$ cells constituted $37-75 \%$ of the inflammatory cells and the ratio of $\mathrm{CD} 4+\mathrm{T}$ cells to CD8+ T cells ranged from 0.8 to 1.8 (Barral et al. 1987, Castes et al. 1989, Martinez-Arends et al. 1991, Esterre et al. 1992, Lima et al. 1994, Isaza et al. 1996). The numbers noted above are consistent with those reported here, indicating that the cellular populations found in active or healed lesions of $L$. (L.) amazonensis-infected rhesus macaques are similar to what has been described in human CL. In this model, there is apparently no correlation between lesional $\mathrm{T}$ cell subsets and those found in blood (Amaral et al. 1996). Results similar to ours were reported in human CL studies (Modlin et al. 1985, Conceição-Silva et al. 1990, Ghosh et al. 1995).

The activation of CD4+ T and/or CD8+ T cells may be essential for the healing that was subsequently observed in these monkeys as has been found in human studies. These T-cell populations proliferating in response to leishmanial antigen stimulation (Uyemura et al. 1993) might be involved in protection from and healing of CL (Maasho et al. 1998). NK cells were relatively abundant in the inflammatory infiltrate as well, and they could play a role in the local control of parasite dissemination (Ridel et al. 1988). In humans, the immunological effectiveness of granulomas appear to be related less to the numbers and location of $\mathrm{T}$ cell phenotypes than the functional aspects of these cells, particularly the ability to generate lymphokines (Modlin et al. 1985, Pirmez et al. 1993). The immunity to the parasite and/or pathogenesis of CL may be explained by the balance of CD4+ type 1 and CD8+ type $2 \mathrm{~T}$ cells, which probably recognize distinct sets of antigen (Uyemura et al. 1993).

The skin immune system plays a critical role in the T-cell response to Leishmania infection (Modlin et al. 1989, Conceição-Silva et al. 1990, Pirmez et al. 1993). The majority (90\%) of lymphocytes present in normal human skin is activated, and approximately evenly distributed between CD4+ inducer and CD8+ suppressor-cytotoxic Tcell subsets (Maasho et al. 1998). Our results indicate that the preferential perivascular localization of activated T lymphocytes (with a predominance of CD8+ T cells) observed in humans (Bos et al. 1987 ) is also the characteristic of normal monkey skin.

Prospects for human immunoprophylaxis with a new generation of safe and effective subunit vaccines is now within our reach (Grimaldi 1995). For a vaccine to elicit a cellular immune response, the class I and class II products of the MHC must present peptide fragments of the vaccine to T-cells. While the repertoire of MHC alleles present among Old World primates may differ, the organization and expression of MHC alleles is similar to that in humans; in contrast, New World monkeys have a smaller MHC when compared to humans (Klein et al. 1993, Kennedy et al. 1997). As the rhesus monkey is an animal system closer phylogenetically to human than the New World primates (Kennedy et al. 1997), the value of this primate model to the researcher lies in its abilitity to produce physiological and immunological responses to leishmanial infection, which are quantitatively similar to those of humans infected with the same agent. The rhesus model should provide an indication of the potential success and/or limitations for candidate vaccines employing similar delivery systems in humans.

\section{REFERENCES}

Agwale SM, Duhlinska DD, Grimaldi Jr G 1998. Response to heterologous leishmanins in cutaneous leishmaniasis in Nigeria - Discovery of a new focus. Mem Inst Oswaldo Cruz 93: 23-27.

Amaral VF, Ransatto VAO, Conceição-Silva F, Molinaro E, Ferreira V, Coutinho SG, McMahon-Pratt D, Grimaldi Jr G 1996. The Asian Rhesus macaques (Macaca mulatta) as an experimental model for study of cutaneous leishmaniasis. Exp Parasitol 82: 34-44.

Barral A, Jesus AR, Almeida RP, Carvalho EM, BarralNetto M, Costa JM, Badaró R, Rocha H, Johnson WD 1987. Evaluation of T-cell subsets in the lesion infiltrates of human cutaneous and mucocutaneous leishmaniasis. Parasite Immunol 9: 487-497.

Bos JD, Zonneveld I, Das PK, Krieg SR, van der Loos CM, Kapsenberg ML 1987. The skin immune system (SIS): distribution and immunophenotype of lymphocyte subpopulations in normal human skin. J Invest Dermatol 88: 569-573.

Castes M, Moros Z, Martinez A, Trujillo D, Castellanos PL, Rondon AJ, Convit J 1989. Cell-mediated immunity in localized cutaneous leishmaniasis patients before and after treatment with immunotherapy or chemotherapy. Parasite Immunol 11: 211-222.

Conceição-Silva F, Dórea RC, Pirmez C, Schubach A, Coutinho SG 1990. Quantitative study of Leishmania braziliensis braziliensis reactive $\mathrm{T}$ cells in peripheral blood and in the lesions of patients with American mucocutaneous leishmaniasis. Clin Exp Immunol 79: 221-226.

Curry AJ, Jardim A, Olobo JO, Olafson RW 1994. Cellmediated responses of immunized vervet monkeys 
to defined Leishmania T-cell epitopes. Infect Immun 62: 1733-1741.

Dennis VA, Lujan R, Chapman Jr WL, Hanson WL 1986. Leishmania donovani: cellular and humoral immune responses after primary and challenge infections in squirrel monkeys, Saimiri sciureus. Exp Parasitol 61: 319-334.

Esterre P, Dedet JP, Frenay C, Chevallier M, Grimaud JA 1992. Cell populations in the lesion of human cutaneous leishmaniasis: a light microscopical, immunohistochemical and ultrastructural study. Virchows Arch A Pathol Anat Histopathol 421: 239247.

Ghosh MK, Nandy A, Addy M, Maitra TK, Ghose AC 1995. Subpopulations of T lymphocytes in the peripheral blood, dermal lesions and lymph nodes of post kala-azar dermal leishmaniasis patients. Scand J Immunol 41: 11-17.

Grimaldi Jr G 1995. Meeting on vaccine studies towards the control of leishmaniasis. Mem Inst Oswaldo Cruz 90: 553-556.

Grimaldi Jr G, Tesh RB 1993. Leishmaniasis of the New World: current concepts and implications for future research. Clin Microbiol Review 6: 230-250.

Grimaldi Jr G, Moriearty PL, Hoff R 1980. Leishmania mexicana: immunology and histopathology in $\mathrm{C} 3 \mathrm{H}$ mice. Exp Parasitol 50: 45-56.

Heinzel FP, Rerko RM, Ahmed F, Pearlman E 1995. Endogenous IL-12 is required for control of of Th2 cytokine responses capable of exacerbating leishmaniasis in normally resistant mice. J Immunol 155 : 730-739.

Isaza DM, Restrepo M, Restrepo R, Caceres-Dittmar G, Tapia FJ 1996. Immunocytochemical and histopathologic characterization of lesions from patientes with localized cutaneous leishmaniasis caused by Leishmania panamensis. Am J Trop Med Hyg 55: 365369.

Kennedy RC, Shearer MH, Hildebrand WH, Simmonds RS 1997. Nonhuman primates and their use in immunologically based investigations. The Immunologist 5/5: 150-156.

Klein J, Satta Y, O'Huigin C, Takahata N 1993. The molecular descent of the major histocompatibility complex. Immunol Reviews 11: 213-244.

Lainson R, Bray RS 1966. Studies on the immunology and serology of leishmaniasis. II. Cross-immunity experiments among different forms of American cutaneous leishmaniasis in monkeys. Trans $R$ Soc Trop Med Hyg 60: 526-532.

Letvin NL, Kim NW, Reinhertz EL, Hunt RD, Lane JH, Schlossman SF 1983. T lymphocyte surface antigens in primates. Eur J Immunol 13: 345-347.

Lima HC, Vasconcelos AW, David JR, Lerner EA 1994. American cutaneous leishmaniasis: in situ characterization of the cellular immune response with time. Am J Trop Med Hyg 50: 743-747.

Lujan R, Dennis VA, Chapman Jr WL, Hanson WL 1986. Blastogenic responses of peripheral blood leukocytes from owl monkeys experimentally infected with Leishmania braziliensis panamensis. Am J Trop Med Hyg 35: 1103-1109.
Lujan R, Hanson WL, Chapman Jr WL, Dennis VA 1987. Antibody responses, as measured by the enzymelinked immunosorbent assay (ELISA), in owl monkeys experimentally infected with Leishmania braziliensis panamensis. J Parasitol 73: 430-432.

Maasho K, Sanchez F, Schurr E, Hailu A, Akuffo H 1998. Indications of the protective role of natural killer cells in human cutaneous leishmaniasis in an area of endemicity. Infect Immun 66: 2698-2704.

Martinez-Arends A, Tapia FJ, Caceres-Dittmar G, Mosca W, Valecillos L, Convit J 1991. Immunocytochemical characterization of immune cells in lesions of American cutaneous leishmaniasis using novel T cell markers. Acta Trop 49: 271-280.

Modlin RL, Pirmez C, Hofman FM, Torigian V, Uyemura K, Rea TH, Bloom BR, Brenner MB 1989. Lymphocytes bearing antigen-specific $\gamma \delta$ T-cell receptors accumulate in human infectious disease lesions. Nature 339: 544-548.

Modlin RL, Tapia FJ, Bloom BR, Gallinoto ME, Castes M, Rondon AJ, Rea TH, Convit J 1985. In situ characterization of the cellular immune response in American cutaneous leishmaniasis. Clin Exp Immunol 60: 241-248.

Mossman TR, Moore KW 1991. The role of IL-10 in cross-regulation of $\mathrm{TH} 1$ and $\mathrm{TH} 2$ responses. Immunol Today 12: A49-53.

Nilsen R, Mshana RN 1987. In situ characterization of the cutaneous immune response in Ethiopian cutaneous leishmaniasis. Scand J Immunol 26: 503-512.

Olobo JO, Reid GD, Githure JI, Anjili CO 1992. IFNgamma and delayed-type hypersensitivity are associated with cutaneous leishmaniasis in vervet monkeys following secondary rechallenge with Leishmania major. Scand J Immunol 1 (Suppl. I): 48-52.

Pirmez C, Cooper C, Paes-Oliveira M, Schubach A, Torigian VK, Modlin RL 1990a. Immunologic responsiveness in American cutaneous leishmaniasis lesions. J Immunol 145: 3100-3104.

Pirmez C, Oliveira-Neto MP, Grimaldi G Jr, Savino W 1990b. Immunopathology of American cutaneous leishmaniasis. Modulation of MHC class II gene products by keratinocytes before and after Glucantime therapy. Mem Inst Oswaldo Cruz 85: 203-209.

Pirmez C, Yamamura M, Uyemura K, Paes-Oliveira M, Conceição-Silva F, Modlin RL 1993. Cytokine patterns in the pathogenesis of human leishmaniasis. $J$ Clin Investig 91: 1390-1395.

Pung OJ, Kuhn RE 1987. Experimental leishmaniasis in the Brazilian squirrel monkey (Saimiri sciureus): lesions, hematology, cellular, and humoral immune responses. J Med Primatol 16: 165-174.

Ridel PR, Esterre P, Dedet JP, Pradinaud R, Santoro F, Capron A 1988. Killer cells in human cutaneous leishmaniasis. Trans $R$ Soc Trop Med Hyg 82: 223226.

Russo DM, Armitage RJ, Barral-Netto M, Barral A, Grabstein KH, Reed SG 1993. Antigen-reactive gamma delta $\mathrm{T}$ cells in human leishmaniasis. $J$ Immunol 151: 3712-3718.

Sobel RA, Blanchette BW, Bhan AK, Colvin RB 1984. 
The immunopathology of experimental allergic encephalomyelitis. Quantitative analysis of inflammatory cells in situ. J Immunol 132: 2393-2401.

Uyemura K, Klotz J, Pirmez C, Ohmen J, Wang XH, Ho C, Hoffman WL, Modlin RL 1992. Microanatomic clonality of $\gamma \delta \mathrm{T}$ cells in human leishmaniasis lesions. J Immunol 148: 1205-1211.

Uyemura K, Pirmez C, Sieling PA, Kiene K, Paes-
Oliveira M, Modlin RL 1993. CD4+ type 1 and CD8+ type $2 \mathrm{~T}$ cell subsets in human leishmaniasis have distinct $\mathrm{T}$ cell receptor repertoires. J Immunol 151: 7095-7104.

Wilson HR, Dickman BS, Childs GE 1979. Leishmania braziliensis and L. mexicana mexicana: experimental cutaneous infections in golden hamsters. Exp Parasitol 47: 270-283. 